\title{
Improving Ethical Attitudes or Simply Teaching Ethical Codes? The Reality of Accounting Ethics Education
}

\begin{abstract}
Ethical instruction is critical in accounting education. However, does accounting ethics teaching actually instil core ethical values or simply catalogue how students should act when confronted with typical accounting ethical dilemmas?

This study extends current literature by distinguishing between moral/ethical and legal/ethical matters and then re-evaluating the effectiveness of ethics training. A cohort of final year accounting students with significant ethical training evaluated ethical scenarios. Half were moral (non-legal) and half contained legal as well as moral components. After further ethical instruction they re-evaluated the scenarios.

Ethical attitudes towards legal/moral issues improved, but attitudes towards moral only issues did not. This questions previous studies which purport to demonstrate the effectiveness of ethical instruction and queries the benefits of accounting ethics education. Are fundamental ethical principles being ignored in an effort to prevent more obvious accounting wrongdoings? Accounting ethics training needs to be reassessed if true ethical improvement is to be achieved.
\end{abstract}

Keywords ethical attitudes, accountants, ethical instruction, ethical v. legal, professional behaviour, empirical study. 


\section{Improving Ethical Attitudes or Simply Teaching Ethical Codes? The Reality of Accounting Ethics Education}

\section{Introduction}

The importance of teaching ethics in accounting education has been long established (De George, 1987). As Christensen et al. (2007) note it is now widely practiced in most good business schools. Extant literature reveals accounting students regard ethics education as not only important to them personally, but they also consider it an important part of their overall business education (Adkins \& Radtke, 2004; Graham, 2012).

However, when teaching ethics as part of any business course, it is a moot point whether instructors are actually instilling core ethical values into students. McPhail (2001 p.282) contends that ethics education should not focus on academic knowledge of ethics alone but also promote "the development of students moral sensibility". Ethics instruction may be simply cataloguing how students should act when confronted with certain fairly typical business ethical dilemmas, particularly in the accounting environment where professional codes of conduct exist for exactly this purpose. Critics such as Whitbeck (1991) express concern that some accounting ethics instruction techniques, such as the dilemma approach to ethics education, may in fact mis-represent moral problems. He argues the dilemmas focus on criteria for moral judgments rather than acquisition of skills, understanding and political wisdom necessary to resolve conflicts. This provides the motivation for the current study.

A review of research into accounting ethical instruction (see literature review section below) notes that almost all studies relate to the legal component of ethical dilemmas. But if accounting students are to be perceived as ethical, the moral component is just as important. The current study therefore hopes to go beyond extant literature in the field of accounting ethical instruction by focussing on the full range of ethical components final year accounting students are supposed to embrace. This includes particularly an examination of any improvement in the ethical concept of professional behaviour, i.e. their attitudes towards ethical scenarios which may not contain any element of legal impropriety, but still raise moral concerns.

The International Federation of Accountants (IFAC, 2014) contributes to the development, adoption, and implementation of high-quality international ethics standards for accountants, 
primarily through its support of the International Ethics Standards Board for Accountants (IESBA). The IESBA's primary document to assist in maintaining ethical standards among accountants is the official text Code of Ethics for Professional Accountants (the code, IESBA 2013). The fundamental principles of the code are outlined at section 100.5 as:

A professional accountant shall comply with the following fundamental principles:

(a) Integrity

(b) Objectivity

(c) Professional Competence and Due Care

(d) Confidentiality, and

(e) Professional Behaviour.

The fifth principle is expanded upon at section 150.1 as follows:

The principle of professional behaviour imposes an obligation on all professional accountants to comply with relevant laws and regulations and avoid any action that the professional accountant knows or should know may discredit the profession. This includes actions that a reasonable and informed third party, weighing all the specific facts and circumstances available to the professional accountant at that time, would be likely to conclude adversely affects the good reputation of the profession. (emphasis added)

All ethical principles consist of a legal component, as noted for example in the non-bold portions of section 150.1 above. However the whole concept of a profession goes beyond merely complying with the law. It is hoped the moral principle of always "doing the right thing" will also be upheld at all times.

A cohort of final year accounting students studying the subject Auditing, was asked their attitudes towards six instances of ethical behaviour, Three involved unethical and illegal behaviour. The other three involved making moral choices, without breaking any laws. Post some traditional accounting ethics teaching, their attitudes were then re-evaluated. Green \& Weber (1997) opined that exposure to whichever code of ethical conduct is applicable to the relevant jurisdiction students are studying in, should be conducive to students progressing to higher stages of moral reasoning. However, the results of this study confirmed the concerns raised earlier, in that students' perceived ethical behaviour improved for those scenarios with 
the legal component. Critically however, no significant differences were discovered in the cases involving a purely moral component.

Our findings therefore bring into question the conclusions drawn from other ethical studies which have shown audit ethical instruction can improve ethical attitudes. Is the improvement noted in these studies due to the fact most of them involved cases with illegalities as well as moral issues? The implications are significant. Ethical training for accountants may need to reconsider its focus, if the aim is to improve ethical awareness rather than simply improving adherence to various accounting codes of ethical instruction. Should accounting educators be teaching applied ethics to their students or is there a need for a stronger underpinning of the topic by focusing on pure ethics and fundamental ethical concepts in the first instance?

The remainder of this study is organised as follows. The next section reviews past literature regarding the effectiveness or otherwise of various ethical training methods on the ethical attitudes of accounting students. Three research questions are then developed. The methodology section which follows describes the experimental design. A results section then analyses and summarises the findings. Finally the summary section concludes the study, considers implications and identifies future research in the area.

\section{Prior literature}

Many studies look at the ethical training of accountants and how effective it is. Typically this is achieved by exposing students to ethical scenarios, case studies or vignettes which usually highlight illegal or extremely questionable behaviour. Hence it is clear to the student that there is a wrong-doing. They are then asked, both before and after receiving appropriate ethical instruction, what action they would take or how ethical they considered someone's behaviour was. The impact of different teaching methods is therefore assessed. For example, O'Leary and Stewart (2013) examined the impact of different teaching methods on third-year accounting students undertaking an auditing course, using five vignettes. The vignettes addressed (1) an accountant being offered a bribe to remain silent in regard to improper accounting practices; (2) an employee who witnesses a senior colleague stealing; (3) deliberate falsification of a job application; (4) inflating expenses and (5) falsifying records. Results suggested all modes of teaching had an effect, with the effect being stronger if student learning style was conducive to the teaching methodology. 
Liyanarachchi and Newdick (2009) looked at the impact of moral reasoning on whistleblowing. They utilised audit-specific ethical situations where (1) an internal auditor discovers bogus invoices, (2) an internal auditor discovers payments being made into an unknown bank account and (3) inflated sales figures are discovered by an internal auditor. They concluded that educators need to improve ethical awareness and this could be achieved through accounting education. Likewise McManus et al. (2012) also explored students' likelihood to whistle-blow. They assessed the impact of two different ethical teaching methods (web-based interactive ethics module versus traditional textbook delivery) using the scenario of an internal auditor detecting the illegal act of an employee creating bogus invoices. Whereas both methods were found to be effective the web-based method was more so.

Bailey \& Soileau (2011) used an illegal software piracy case study approach to expose students to potential ethical dilemmas they may encounter in their professional careers. Ninety per cent of the students considered it an effective accounting ethics learning experience.

Sweeney and Costello (2009) provided business students (a mixture of accounting and nonaccounting) with four scenarios. These were (1) expense falsification, (2) manipulation of earnings by decreasing bad debts expenses and holding sales open past the month-end, (3) manipulating capital expenditure orders to by-pass company policy of board approval and (4) by-passing credit control policy to obtain a large sale to meet budget and ensure bonuses for management. They noted the accounting students were more adept at identifying unethical behaviour than the non-accountants and opined:

This suggests that accounting education may be effective in raising accounting students' awareness of what constitutes an ethical dilemma. (p.92).

However, they immediately followed this possible acknowledgement of the success of ethical instruction in improving ethical awareness by acknowledging that:

.... this may not translate into improved ethical judgement and intentions. (p.92).

Green and Weber (1997) explored how and when ethics should be taught in order to increase the effectiveness of accounting ethics education. Presenting the scenario of a manager discovering evidence of fraud and then being advised to shred the evidence, they initially found no difference in moral reasoning between accounting and non-accounting students. However, subsequent to the accounting students undertaking an auditing course which emphasised the AICPA code of ethics, the accounting students were able to reason at a higher level than the 
non-accounting students. Similarly, Fulmer \& Cargile (1987) noted that accounting students tended towards a more ethical viewpoint than non-accounting students in a study involving a scenario where management of a company purposefully distorted its financial condition when reporting to the parent company. However, just like the Sweeney and Costello (2009) summation above, Fulmer \& Cargile (1987) also cautioned that having a more ethical viewpoint does not necessarily translate into actually acting in a more ethical manner.

All the above studies appear to point towards the positive impact on the ethical education of accounting students, of integrating ethical training into accounting programmes. A study by O'Leary (2012) noted twenty studies which evaluated the success (to varying extents) of different accounting ethics training techniques. These included: lectures with accompanying class notes and exercises; guest lecturers such as local business people, business leaders, philosophers; guided examination of existing ethical codes; vignettes with explanatory interventions; viewing professionally produced videos; class discussions; case studies; group assignments and role playing.

But as mentioned previously, is this ethical education actually improving ethical understanding, or merely highlighting the correct way to act in certain scenarios? All the case studies/vignettes/scenarios referred to in the studies above related to clearly illegal, or at best very obviously inappropriate, behaviour. Indeed, research exists that suggests accountants in general take a legalistic approach to ethics (i.e. complying with the law rather than with ethical principles. Gray, Bebbington and McPhail (1994) suggest university accounting teaching practice tends to be dominated by "techniques acquisition" policies (1994, p.52). As a result, the level of ethical maturity and reasoning experienced by accounting students and exhibited by accounting practitioners is not as developed as it should be. Similarly Wyer (1987) and Puxty, Sikka and Willmott (1994) expressed concern over the manner in which accounting/auditing textbooks cover ethical situations. Both studies noted the predominant focus on Codes of Professional Conduct rather than fundamental principles. This again suggests a strong legalistic approach. Cooper et al. (2008) stress the need to design ethical training which achieves two aims, promotes ethical awareness as well as improve decisionmaking. Their study highlights previous criticisms of some ethics education methods which fail to promote the former and concentrate on the latter aim.

Considering the ethical principles issue, as opposed to legal issues, when Adkins and Radtke (2004) asked students and faculty members seven questions pertaining to the importance of 
accounting ethics education, two questions included the word 'moral'. Interestingly, students rated the importance of accounting ethics education with the goal of "[r]elate accounting education to moral issues' and '[d]evelop a "sense of moral obligation"” significantly higher than faculty members. A possible explanation for this is that the student body might be more morally sensitive than the faculty members (possibly disillusioned and somewhat cynical after years of real world experience) with whom they were compared. However, it is hoped this is not the case although the possibility must be recognized. A more likely inference according to Adkins and Radke (2004) is that students see these goals as highly important, because they have difficulty in discerning what is right when faced with an issue that is legal, yet morally questionable.

This study therefore goes beyond previous research in the area in that it also focuses upon the fifth ethical component of the IFAC code (IFAC, 2014) mentioned above, namely professional behaviour, as well as the more traditional ethical components such as integrity etc. This involves evaluating moral issues as well as legal issues in an ethical context. Therefore this study allows for a comparison of changes in perceived ethical behaviour in instances of legal/moral as opposed to purely moral environments. This should help evaluate whether teaching ethics really improves the ethics of the recipients, in terms of their overall appreciation of ethical issues or does it merely improve their ability to apply the appropriate code of conduct.

Three research questions (RQ) are derived from the above discussion. As the majority of studies have purportedly shown the benefits of ethical training for accounting students the first two RQs are posed as follows:

RQ1: Will accounting students' attitudes towards ethical scenarios involving a legal and moral component improve, post ethical instruction?

RQ2: Will accounting students' attitudes towards ethical scenarios involving only a moral component improve, post ethical instruction?

Based upon previously mentioned studies focusing on concerns about the actual effectiveness of ethical instruction in improving actual ethical awareness, as opposed to simply improving the ability to appropriately apply ethical codes of behaviour, the final RQ is posed as follows:

RQ3: Will accounting students' attitudes towards ethical scenarios involving a legal and moral component, change at a different rate to their attitudes towards ethical scenarios involving only a moral component, post ethical instruction? 


\section{Methodology}

\section{Participants}

A cohort of final year undergraduate accounting students undertaking a final semester Auditing class provided the participants. This cohort had received significant ethical instruction, throughout their degree programme. Appendix 1 shows a sub section of the mapping of graduate skills (assurance of learning goals) employed through the Bachelor of Commerce programme at the participants' University. From Appendix 1 it is clear this group of students received some combination of ethical and legal instruction in 7 of the 24 courses of their basic degree before they arrived at the Auditing course. This then became the eighth course which included some legal/ethical component. This component, as used during this particular Auditing course is explained in the next paragraph. It is important to note therefore that these students had a reasonable exposure to ethical concepts, thinking and application in an accounting environment before they arrived at this point in their studies. The final year auditing course was then a further topic area in which to appreciate the importance of ethics in the working environment.

This Auditing course contained a significant component of accounting ethics training. Students received a full lecture ( 2 hours) on ethics in accounting/auditing including an introduction to ethics, ethical theories in general and then their specific application in an accounting context. The IFAC Code of Professional Conduct mentioned previously was reviewed in some detail. Students had readings and a full tutorial the following week which incorporated general questions on ethical dilemmas and even solving an audit ethical case study involving a breach of confidentiality.

\section{Survey Instruments and distribution}

Participants completed two versions of a survey instrument. In the first week of classes, a survey instrument containing some basic demographic details followed by six ethical scenarios was administered to students during class time. Three of the scenarios contained legal and moral issues but the other three had no illegalities involved, only moral (professional behaviour) issues. At the end of each of the scenarios students were asked to evaluate the ethical behaviour of an accounting student or accounting trainee with an accounting firm. They evaluated by selecting one response from five alternatives as follows: Very Unethical, 
Unethical, Neutral, Ethical, Very Ethical. A 5 point Likert scale was used with 1= very unethical and $5=$ very ethical. Refer Appendix 2 for an abbreviated version of the survey instrument, including two scenarios, one legal and moral case and one solely moral. Completion of the questionnaire took approximately 15 minutes.

The three legal and moral scenarios are accounting-related, portraying scenarios in which a recently graduated accountant has spent six months in his/her first job and is faced with an ethical dilemma involving an illegal activity. These scenarios were numbered 1, 3 and 5 . Scenario 1 depicts an assistant accountant working in a company being offered a 'payment' by the Chief Accountant to keep silent regarding improper accounting practices. Scenario 3 depicts a trainee accountant in an accounting firm being pressured to inflate travel expenses for reimbursement. Scenario 5 depicts a trainee accountant in an accounting firm being pressured to make necessary adjustments to a client's accounts, in order for a bank loan to be approved.

The three moral (professional behaviour) scenarios considered ethical attitude issues whereby a student, or trainee accountant who has commenced work in an accountancy practice, has to make a moral decision. Nothing blatantly illegal is occurring. Rather, the issues concern factors such as those outlined in section 110.150 of the IFAC code mentioned in the introductory section, which would question whether an accountant has acted in a way which would discredit the profession or could be concluded as adversely affecting the good reputation of the profession. These scenarios were numbered 2, 4 and 6 .

Scenario 2 depicts a student who has acted as treasurer to a social club and at the end of his/her term treats him/herself and their partner to a dinner, out of the club's surplus funds. It is not illegal according to the clubs constitution, the issue of what to do with surplus funds is simply not addressed. Scenario 4 involves a student interpreting job application requirements differently to his/her colleagues and so applying for a position his/her peers do not apply for, even though just as qualified. The application criteria required previous experience, which although not explicitly explained, obviously meant full-time experience. One student decides to interpret this as part-time experience and so applies, knowing his/her colleagues will not be doing so. Finally scenario 6 involves a trainee accountant in an accounting firm not telling his/her firm some information about a job applicant he/she knows has acted inappropriately in the past.

Confidentiality was considered critical in order to encourage participation and integrity of responses. The survey instruments were therefore anonymous and participants were not asked 
to identify themselves. This approach has its disadvantages in that it precludes subsequent matched pairing of responses, when participants completed the second version of the survey instrument. Therefore statistical analysis of the results is limited to basic ANOVA analyses. However, as earlier studies like Nelson and Wittmer (2001) and Spence and Wadsworth (2002) attest, some students withdraw from participation in certain ethical studies partly because of their desire not to express their beliefs publically. The authors of this study also considered answers had a better chance of being genuine and not subject to "demand effects" if anonymity was assured. Hence, in the interests of increasing both the quantity and quality of responses, over the opportunity for more robust results analysis, results of each group were pooled and analysed as a group with no attempt at individual matching.

To further strengthen the validity of the study, it was also stressed to participants that completion of the survey did not form part of the assessment procedures for the course, that there were no right or wrong answers and they were to answer according to how they genuinely felt at the time. The completion was also supervised so no discussions were possible. Finally the six scenarios were mixed as alternate legal and moral cases and then moral cases to avoid pattern effects. This first distribution of the survey instrument yielded 48 useable responses.

After the students had been subject to the teaching ethics component of the course, they completed the second version of the survey instrument in week five of the course. This was a total surprise to the participants since they had not been told they would be repeating this exercise, when first completing it in week 1. The second version involved re-evaluating the ethical vignettes they had done four weeks previously. The same demographic details were requested and two further questions asking (i) whether the students could remember the answers they had given the first time, and (ii) whether or not they thought their ethical attitudes had changed, were asked. This (second) distribution of the survey instrument yielded 37 useable responses.

\section{Pre-study pilot test}

As mentioned in the literature review section, it appears evaluation of purely moral ethical dilemmas in an accounting environment has not been covered to the same extent as evaluation of legal and moral dilemmas. Therefore, in the semester prior to the one targeted for this study, it was decided to perform a pre and post ethical instruction evaluation of moral ethical dilemmas only, before integrating them with the more common legal and moral dilemmas 
usually employed in such studies. O'Leary and Cameron (2014) therefore conducted a pilot test on the cohort of students in the previous semester. The methodology was identical to that described above yielding 53 pre-instruction evaluations of six ethical scenarios with a moral content only and 40 follow-up post instruction evaluations. The six scenarios were the three moral dilemmas described above, plus three other ethical dilemmas with no legal issues involved. (These involved: (i) an extension to scenario 2 above, in that the student invites the whole committee to lunch; (ii) a student filling in a class attendance register for a fellow student who does not turn up; and (iii) evaluation of the student in the previous case who requested the favour). Table 1 summarises the results of this pilot test.

\section{Table 1 here}

The results appeared to support the concerns which motivate this current study. Of the six scenarios a significant improvement in perceived ethical behaviour, post ethical training, was not achieved in any of the six cases. The findings suggest RQ2 of the current study should be answered in the negative. However, this pilot test was not considered a valid "stand alone" research study as the purpose of this current research is to compare ethical dilemmas with a legal and moral component to those with a moral component only, and the pilot test only offered one type of dilemma. However it provided the basis for the structure of the current survey instrument, which can assist in achieving the stated aim.

\section{Results}

Returning to the current study, Table 2 lists the raw data which enables us to perform all subsequent analyses. This data consists of the frequency distribution of each individual groups' responses to each individual scenario and the overall group mean for each scenario, both pre and post instruction.

A reliability test was performed initially to analyse the data for consistency. A Cronbach's alpha score of .678 was obtained when the scores of the six scenarios were analysed. This implies $68 \%$ of the items are measuring the same construct. Murphy and Davidshofer (1988) consider a Cronbach score above 0.6 as acceptable, so the reliability of the data is supported.

\section{Table 2 here}


Basic $A N O V A$ s were then performed comparing the mean response on a group basis to the scenarios pre and post instruction. Considering RQ1, the impact of ethical instruction on trainee accountants' behaviour when facing a legal and moral dilemma, this entailed comparing the evaluations for scenarios 1, 3 and 5. Table 3 provides this analysis.

\section{Table 3 here}

All three means increased substantially post instruction, two of them at statistically significant levels. This indicates participants willingness to engage in more ethical behaviour, post ethical instruction than prior to the instruction. Recall, as per the methodology section, the scenarios are unethical but the 5 responses range from the (low score) unethical to (high score) ethical. Hence as a mean increases this implies the participants are selecting a more ethical option.

Therefore this result would appear to indicate the benefits of ethical training for accounting students and supports the results of several such studies in the area, as mentioned previously. RQ1 is therefore answered in the affirmative.

RQ2, the impact of ethical instruction on trainee accountants' behaviour when facing a moral dilemma, was then reviewed. This entailed comparing the evaluations for scenarios 1, 3 and 5 . Table 4 provides this analysis.

\section{Table 4 here}

As is evident from Table 4 this time there was no significant difference post ethical instruction. All three means increased post instruction but only by miniscule amounts. There was no significant impact. This appears to suggest that accounting ethics training had no effect on students' perceived ethical decision making when it came to evaluating moral dilemmas which did not have a legal content. The pilot study performed on a separate cohort of students in the previous semester (as outlined in the methodology section above) produced a similar result. Green \& Weber's (1997) contention, mentioned previously, that exposure to the ethical code should be conducive to students progressing to higher stages of moral reasoning, is not supported. RQ2 is therefore answered in the negative.

Analysis of the differences between the responses to scenarios 1, 3 and 5 as opposed to scenarios 2, 4 and 6 was then conducted to provide further evidence with which to respond to RQ3. Firstly the raw data was again analysed and the differences in means between pre and post instruction completion of the surveys were examined. Table 2 column 7 lists these means. 
Pre and post mean differences per scenario were then ranked from 1 (largest movement) to 6 (smallest movement). The ranking position was then posted to column six of Tables 3 and 4. Table 3 contains the three biggest differences (average difference $=0.47$, untabulated) and these were all the legal and moral scenarios. There was then a significant gap to the final three differences (average difference $=0.08$, untabulated) and these were for scenarios in Table 4, the moral only scenarios. Hence a very significant difference exists between the movement in ethical attitudes pre and post instruction, depending upon the type of scenario (legal and moral or just moral).

The results of the 6 scenarios were then correlated to examine any further patterns. Table 5 summarises the results.

\section{Table 5 here}

As per row three of Table 5, the results of scenario 1 correlated with the results of scenarios 3 and 5 at the highest significance level (significant@.000). This result suggests strong similarities among respondents' treatment of these three legal and moral ethical scenarios. From their initial (pre-instruction) analysis of the situation, through to how ethical training influenced their re-analysis (post-instruction) the participants evaluated these cases very similarly. However when one examines column seven of Table 5, there is no significant correlation between any of the three moral scenarios. Scenarios 2, 4 and 6 do not reveal any statistically significant correlations. This would tend to suggest participants considered these scenarios all as different types with little link to each other. Similarly, the three moral dilemmas appear to have little link to the previous three scenarios which had a legal component. Scenario 1 does correlate with scenario 2 and scenario 3 correlates with scenario 4 , but both are at a weaker significance level than the level achieved by the three legal and moral scenarios $(1,3$ and 5) as mentioned above.

Standard $A N O V A$ analyses were performed on the three demographic details (gender, student status and age) collected in both versions of the survey, see Appendix 2. Considering gender firstly, as per Table 2 , there were 48 completions pre-instruction and 37 post-instruction, giving a total of 85 observations. These were split as to male/female as follows ( $n=38 / 47)$. No significant differences were found across scenarios between male/female responses in any of the pre, post or combined analyses. Similarly the 85 observations were categorised on the basis of domestic/international student status using the following numbers $(n=43 / 42)$. Here again all three analyses, pre, post and combined showed no significant differences. An analysis of 
the 85 observations based on age categories of 18-21 yrs, 22-28 yrs and 28+ yrs $(n=27 / 39 / 19)$ revealed the oldest age group selected statistically significantly more ethical attitudes than the younger two groups in two of the six scenarios. As this significant difference appeared both in the pre and post stage the ethical instruction did not cause the differences, so this finding is beyond the scope of the current study. The result does support the findings of some previous studies which revealed age can impact ethical attitudes in an accounting environment.

Finally, responses to the last two demographic questions, only answered in the second version of the survey and referred to in the methodology section above, were analysed. $43 \%$ of students said they could not remember the responses they gave when they completed the survey preinstruction and 19\% said they were unsure. This only left $38 \%$ of students who claimed they could remember their responses first time. This strengthens the validity of the study as the proportion of students who could potentially have given a more ethical answer the second time, purely to demonstrate they had improved (rather than reflect their actual ethical attitudes) is less than those who could not do so, because they did not remember the first response. Even though the design of the study was intended to minimise such potential behaviour it is recognised as a limitation. But this result reduces the risk of such behaviour impacting the overall analysis of findings.

The results of the final question, whether the students thought their ethical attitudes had changed, were then analysed. $35 \%$ of students considered their ethical attitudes had not changed and $24 \%$ were unsure. This left $41 \%$ of students considering the ethical instruction had impacted them. This would appear to add further credence to the concept that RQ3 should be answered in the affirmative. Over $40 \%$ of the students felt their ethical attitudes had been impacted, and indeed there was significant perceived improvement as regards the legal and moral issues. But as mentioned above, improvement in the moral only scenarios was absolutely negligible. This could be interpreted therefore as saying that students consider their ethical attitudes have been improved because they respond more ethically to legal/moral issues whereas in fact their fundamental ethical attitudes (professional behaviour, acting ethically) has not in fact improved. This is discussed further below.

\section{Summary}

Post the global financial crisis ethics of business people, including accountants (Snyder, 2011) are being criticised. Hence, acting with integrity should be paramount at all times. A study by Andre (2103) opines how well businesses perform in areas such as corporate social 
responsibility and stakeholder inclusion, is dependent upon how well grounded their core 'care ethics' are. This highlights the importance of accounting ethics training. But current ethics training has been criticised by McPhail (2001) among others, as not addressing the fundamental ethical development of accounting students.

In psychological terms, possessing an ethical mind-set involves consistent practice of ethical principles (Gardner, 2007). Hence, the establishment of solid core principles which underpin all subsequent practice appears logical. However, when accounting ethics are currently being taught, is the focus too much on what is 'legal' or what follows the appropriate professional code of conduct and not enough on overall morals and attitudes? A review of the extant literature which purports to attest to successful ethical instruction in accounting training environments, noted the preponderance of obviously legal issues utilised during the research.

The current study therefore extends the focus to incorporate all five core accounting ethical principles, including the fundamental ethical principle of professional behaviour. When a group of accounting students were exposed to ethical training, which included exposure to an ethical code particular to their profession, their evaluation of ethical behaviour in legal and moral scenarios improved. But for moral only scenarios it did not improve, post instruction. Results suggest that the teaching of ethics does not improve the moral attitudes of the students, in contrast to prior studies which demonstrated improved ethical attitudes when specific ethical dilemmas, with a significant legal component, were tested.

The implications are considered significant for accounting ethics educators. The overall question as to what is the fundamental point of ethics training must be considered. Is it to raise the overall ethical level and awareness of the students or to simply get them to try and act appropriately in specific accounting ethical situations, such as bribery and/or cheating dilemmas, they are likely to encounter? If the former is the case, then how we proceed with ethical instruction at business colleges may need reviewing. Referring to the results above and the final demographic question, $41 \%$ of students thought their ethical attitudes had been impacted by teaching intervention. But this was only reflected in their attitude to legal issues. Their core ethical moral attitudes showed no sign of improvement. As per the introductory section of this study, it was hoped to shed more light on whether accounting ethics education actually improves ethical attitudes or simply teaches ethical codes. Findings suggest the latter is the only goal being achieved using current methods. The studies referred to in the literature review similarly appear to attest to students gaining a better understanding of ethical codes of 
conduct post instruction. No evidence of improved moral understanding has been ascertained, thus querying the real impact of accounting ethics education. Currently it does not appear to result in improved behaviour or awareness, merely improved application of appropriate rules for professional behaviour.

Therefore, considering accounting ethical education, should business ethics be taught as a stand-alone topic (Loeb, 1998) should it be integrated throughout the entire programme (Bodkin and Stevenson, 2007) or should it be combined with a general ethics course, followed by a capstone course in ethics and professionalism (Thomas, 2004)? Should the focus on pure ethics be significantly increased before application to the accounting environment is added on? Each option has resource implications along with other critical issues to be considered, such as how effective they would be. But if the ethical behaviour of accountants is to be improved these issues have to be addressed.

The current study has a few limitations which also pave the way for future research. Firstly, although much is made in this study of the difference between 'legal and moral' ethical dilemmas and solely 'moral' ethical dilemmas, it is difficult to always make a definitive difference between the two types. Future research could concentrate more specifically on the differing types of ethical issues and test all different types. Second, the sample size could be extended in future studies. Great care was taken in selecting the sample of participants for this study as evidenced by the discussion of their ethical training up to this point, the additional steps taken to strengthen the validity of the study, etc. It is considered a high quality participant was utilised as a result. But larger numbers in subsequent tests could prove more beneficial. Future research could therefore extend this sample to other institutions. Third, whether the responses participants gave are a true reflection of their ethical intentions is always debateable. Whereas all care was taken and many assurances given to participants, to attempt to ensure an honest response, the risk that participants give what they consider a more appropriate response, than one that truly expresses their actual feelings, must be acknowledged.

Acknowledgements: The authors wish to thank organisers and delegates of the Royal Melbourne Institute of Technology, Accounting Educators' Conference and the Accounting Education - Research Interest Group of the Department of Accounting Finance and Economics, Griffith University, Australia for their helpful comments which assisted the preparation of this article. 


\section{References}

Adkins N. \& Radtke R.R. (2004). "Students' and faculty members' perceptions of the importance of business ethics and accounting ethics education: Is there an expectations gap?" Journal of Business Ethics, 51:3, 279-300.

Andre K. (2013). "The ethics of care as a determinant for stakeholder inclusion and CSR perception in business education." Society and Business Review. 8:1, 32 - 44.

Bailey, C.D. \& Soileau, J.S. (2011). "Q-analytics: An ethics case on unlicensed software usage". Journal of Accounting Education, 29:1, 50-59.

Bodkin, C.D. and Stevenson T.H.. (2007). "University Students' Perceptions Regarding Ethical Marketing Practices: Affecting Change Through Instructional Techniques". Journal of Business Ethics 72, 207-228.

Christensen, L.J., Peirce, E., Hartman, L.P., Hoffman, W.M. and Carrier, J. (2007), "Ethics, CSR and sustainability education in the Financial Times Top 50 Global Business Schools: baseline data and future research directions", Journal of Business Ethics, 73:4, 347-68.

Cooper, B.J., Leung, P., Dellaportas, S. Jackling, B. \& Wong, G. (2008). "Ethics Education for Accounting Students-a Toolkit Approach". Accounting Education: An International Journal, $17: 4,405-430$.

De George, R. T. (1987). "The Status of Business Ethics: Past and Future”. Journal of Business Ethics. 6:3, 201-211.

Fulmer, W.E., \& Cargile, B.R. (1987). "Ethical Perceptions of Accounting Students: Does Exposure to a Code of Professional Ethics Help?" Issues in Accounting Education, 3:1, 207219.

Gardner, H. (2007). 'The Ethical Mind'. Harvard Business Review, March, 51-56.

Graham A. (2012). "The Teaching of Ethics in Undergraduate Accounting Programmes: The Students' Perspective." Accounting Education: An International Journal. 21:6, 599-613.

Gray, R. Bebbington J. \& McPhail K. (1994). "Teaching ethics in accounting and the ethics of accounting teaching: educating for immorality and a case for social and environmental accounting education.” Accounting Education: An International Journal, 3:1, 51-75.

Green, S. \& Weber, J. (1997). "Influencing Ethical Development: Exposing Students to the AICPA Code of Conduct." Journal of Business Ethics 16, 777-790. 
International Ethics Standards Board for Accountants (IESBA). (2013). "Code of Ethics for Professional Accountants." www.ifac.org/iesba/handbook

International Federation of Accountants (IFAC). (2014). www.ifac.org.

Liyanarachchi, G \& Newdick, C (2009). "The impact of moral reasoning on whistle-blowing: New Zealand evidence.” Journal of Business Ethics, 89, 37-57.

Loeb, S. E.: 1998, 'A Separate Course in Accounting Ethics: An Example' Advances in Accounting Education 1, 235-250.

McManus L. Subramaniam N. \& James W. (2012) “A Comparative Study of the Effect of Web-Based Versus In-Class Textbook Ethics Instruction on Accounting Students Propensity to Whistle-Blow'. Journal of Education for Business. 87:6, 33-342.

McPhail, K. (2001). "The Other Objective of Ethics Education: Re-humanising the Accounting Profession -- A Study of Ethics Education in Law, Engineering, Medicine and Accountancy." Journal of Business Ethics, 34:3/4, 279-298.

Murphy, K. R. \& Davidshofer C. (1988). "Psychological Testing: Principles and Applications". Engle-wood Cliffs: NJ: Prentice-Hall.

Nelson, D.R.\& Wittmer, D.P. (2001). "Developing a learning community approach to business ethics education". Teaching Business Ethics, 5(3), 267-281.

O’Leary C (2012). "Semester Specific Ethical Instruction for Auditing Students”. Managerial Auditing Journal (UK). 27:6, 598-617.

O’Leary C. \& Cameron R. (2014). "Accounting Ethics Education- Raising Ethical Standards or Just Teaching Codes of Ethics?" RMIT Accounting Educators' Conference. Melbourne, Australia. 24 November.

O'Leary, C. \& Stewart, J. (2013). "The Interaction of Learning Styles and Teaching Methodologies in Accounting Ethical Instruction." Journal of Business Ethics, 113:1, 225-241.

Puxty, A. Sikka, P. and Willmott, H. (1994), "(Re)forming the circle: education, ethics and accountancy practices". Accounting Education: an international journal, 3(1), 77-92.

Snyder. H.W. (2011). "Client confidentiality and fraud". Fraud Magazine. Jan-Feb. www.fraud-mgazine.com Association of Certified Fraud Examiners. Texas.

Spence, L. J., \& D. Wadsworth. (2002). Using an Electronic Bulletin Board in Teaching Business Ethics: "En Route To A Virtual Agora". Teaching Business Ethics 6(3), 335-354.

Sweeney B. \& Costello F. (2009). "Moral Intensity and Ethical Decision-making: An Empirical Examination of Undergraduate Accounting and Business Students". Accounting Education: An International Journal. 18:1, 75-97. 
Thomas, C. W. (2004). "An Inventory of Support Materials for Teaching Ethics in the PostEnron Era.” Issues in Accounting Education. 19:1, 27-52.

Whitbeck C. (1991). “The Trouble With Dilemmas : Rethinking Applied Ethics'. Working Paper. Quoted in Reiter S.A. (1996). "The Kohlberg - Gilligan controversy : lessons for accounting ethics education" Critical Perspectives on Accounting 7, 33 - 54.

Wyer, J. C. (1987) "Report of the national commission on fraudulent financial reporting: the potential for educational impact." Report of the National Commission on Fraudulent Financial Reporting. 


\section{Bachelor of Commerce (Accounting) Curriculum Map}

\begin{tabular}{|c|c|c|c|c|c|c|c|c|c|c|}
\hline $\begin{array}{l}\text { The B Comm } \\
\text { Graduate } \\
\text { will: } \\
\text { Objectives }\end{array}$ & $\begin{array}{l}\text { Intro to } \\
\text { Bus Law }\end{array}$ & $\begin{array}{c}\text { Corp } \\
\text { Fin }\end{array}$ & $\begin{array}{l}\text { Fin } \\
\text { Acc }\end{array}$ & $\begin{array}{l}\text { Company } \\
\text { Acc }\end{array}$ & $\begin{array}{l}\text { Mgnt } \\
\text { Acc }\end{array}$ & $\begin{array}{c}\text { Company } \\
\text { Law }\end{array}$ & $\begin{array}{c}\text { Accounting } \\
\text { Theory \& } \\
\text { Practice }\end{array}$ & $\begin{array}{l}\text { Strat } \\
\text { Mgmt } \\
\text { Acc }\end{array}$ & $\begin{array}{c}\text { Revenue } \\
\text { Law }\end{array}$ & Auditing \\
\hline $\begin{array}{l}2.1 \\
\text { Demonstrate } \\
\text { knowledge } \\
\text { and }\end{array}$ & $\begin{array}{l}\checkmark \checkmark \text { (legal) } \\
\checkmark \text { (ethic) }\end{array}$ & - & - & $\begin{array}{l}\checkmark \checkmark \\
\text { (legal) } \\
\checkmark \text { (envir) }\end{array}$ & $\begin{array}{c}\checkmark \\
\text { (envir) }\end{array}$ & $\begin{array}{l}\checkmark \checkmark \\
\text { (ethic \& } \\
\text { legal) }\end{array}$ & $\begin{array}{l}\checkmark \checkmark \\
\text { (ethic \& } \\
\text { envir) }\end{array}$ & $\begin{array}{c}\checkmark \\
\text { (envir) }\end{array}$ & $\checkmark \checkmark$ (legal) & $\begin{array}{l}\checkmark \checkmark \text { (ethic } \\
\& \text { legal) }\end{array}$ \\
\hline $\begin{array}{l}\text { application of } \\
\text { ethical, legal } \\
\text { and/ or } \\
\text { environmental } \\
\text { responsibility } \\
\text { of individuals } \\
\text { and } \\
\text { organisations } \\
\text { in society }\end{array}$ & XX (legal) & - & - & $\begin{array}{l}\mathrm{XX} \\
\text { (legal) }\end{array}$ & $\begin{array}{l}X \\
\text { (envir) }\end{array}$ & $\begin{array}{c}\text { XX } \\
\text { (legal) }\end{array}$ & $\begin{array}{l}\text { XX1 } \\
\text { (ethics \& } \\
\text { envir) }\end{array}$ & $\begin{array}{c}\mathrm{X} \\
\text { (envir) }\end{array}$ & XX (legal) & $\begin{array}{l}\text { XX (ethic } \\
\& \text { legal) }\end{array}$ \\
\hline
\end{tabular}

Key: Teaching \& learning activities (TLAs): $\checkmark=$ objective is addressed through TLAs. $\checkmark \checkmark=$ very strong - TLAs designed to promote thorough, deep \& active learning in relation to desired objective Code for assessment: $\mathrm{X}=$ objective is addressed. $\mathrm{XX}=$ very strong - thorough, deep assessment of objective 


\section{APPENDIX 2 - ABRIDGED SURVEY INSTRUMENT}

\section{Demographic Details}

1. Please indicate your gender, student status and age group:

\begin{tabular}{|l|l|l|l|l|}
\hline Gender & & Male & Female & \\
\hline Student status & & Domestic & International & \\
\hline Age group & & $18-21$ & $22-28$ & $28+$ \\
\hline
\end{tabular}

Now, please answer the following 6 ethical dilemmas

\section{Ethical Scenario 3 - Legal and Moral 1}

You have completed your degree and have spent six months in your first job, as a trainee accountant at an accounting firm. For the purpose of training and development, the firm sends you and two other accounting staff to attend a two-day seminar interstate. You have previously worked with the two accountants and have a good working relationship with them. During the trip, both inform you of their plan to inflate their travel expenses for reimbursement by the sum of $\$ 300.00$. You get paid approximately $\$ 600.00$ per week. They encourage you to do the same so that it won't look suspicious and there will be subsequent training seminars interstate.

\section{Ethical Scenario 2 - Moral 2}

You are treasurer of the accounting students' football club. The club raises funds through membership fees and sponsorships from local businesses. During a highly successful year you organised everything, as the other committee members decided you were so good they left it all to you to do. The highlight of the year was sending both a male and female team to the interUniversity cup, which your Uni had never previously participated in. You have just balanced the books for the annual general meeting and there is a surplus of $\$ 500$ so to reward yourself for your efforts all year, you treat yourself and your partner to a nice dinner at a good restaurant the cost of which is $\$ 100$. You carefully check the club's constitution firstly and it states the treasurer has permission to spend money as he/she thinks appropriate, so you are not doing anything illegal. You charge the amount to administration expenses.

I consider the action above to be (tick one box):

\begin{tabular}{|l|l|l|l|l|}
\hline $\begin{array}{l}\text { Very } \\
\text { Unethical }\end{array}$ & Unethical & Neutral & Ethical & $\begin{array}{l}\text { Very } \\
\text { Ethical }\end{array}$ \\
\hline & & & & \\
\hline
\end{tabular}

\footnotetext{
${ }^{1}$ Participants were NOT given this heading, they just saw "Ethical scenario \#"

${ }^{2}$ lbid.
} 


\section{$\underline{\text { Tables }}$}

\begin{tabular}{|c|c|c|c|c|c|c|c|c|c|}
\hline \multicolumn{10}{|c|}{ Table 1. Pilot Test of "Moral" Scenarios Responses By Group } \\
\hline \multirow[b]{2}{*}{ Scenario (Sc) } & VU(1) & $\mathbf{U}(2)$ & \multicolumn{2}{|c|}{ N (3) } & \multicolumn{2}{|c|}{$\mathbf{E}(4)$} & \multicolumn{2}{|c|}{ VE(5) } & \multirow[t]{2}{*}{ Mean } \\
\hline & $\mathbf{N} \%$ & N \% & & & & $\%$ & & & \\
\hline \multicolumn{10}{|l|}{ Sc1 } \\
\hline Pre-Ins $(\mathrm{N}=53)$ & 1325 & $25 \quad 53$ & 4 & 7 & 6 & 11 & 2 & 4 & 2.17 \\
\hline Post-Ins $(\mathrm{N}=40)$ & 923 & 2460 & 2 & 5 & 5 & 12 & 0 & 0 & $2.08 \mathrm{n} / \mathrm{s}$ \\
\hline \multicolumn{10}{|l|}{ Sc2 } \\
\hline Pre-Ins & 24 & $\begin{array}{ll}7 & 13 \\
\end{array}$ & 24 & 45 & 14 & 27 & 5 & 9 & 3.25 \\
\hline Post-Ins & 25 & $\begin{array}{ll}3 & 7 \\
\end{array}$ & 22 & 55 & 13 & 33 & 0 & 0 & $3.15 \mathrm{n} / \mathrm{s}$ \\
\hline \multicolumn{10}{|l|}{ Sc3 } \\
\hline Pre-Ins & 24 & $17 \quad 32$ & 11 & 21 & 20 & 37 & & 4 & 3.06 \\
\hline Post-Ins & $\begin{array}{ll}0 & 0 \\
\end{array}$ & $\begin{array}{ll}8 & 20 \\
\end{array}$ & 12 & 30 & 18 & 45 & 2 & 5 & $3.35 \mathrm{n} / \mathrm{s}$ \\
\hline \multicolumn{10}{|l|}{ Sc4 } \\
\hline Pre-Ins & $\begin{array}{ll}6 & 11\end{array}$ & $34 \quad 64$ & 81 & 15 & 1 & 2 & & 6 & 2.25 \\
\hline Post-Ins & 25 & $28 \quad 10$ & 7 & 18 & 2 & 5 & & 2 & $2.30 \mathrm{n} / \mathrm{s}$ \\
\hline \multicolumn{10}{|l|}{ Sc5 } \\
\hline Pre-Ins & $\begin{array}{ll}10 & 19 \\
\end{array}$ & \begin{tabular}{|ll}
33 & 63 \\
\end{tabular} & $\begin{array}{ll}5 & 1 \\
\end{array}$ & 10 & 2 & 4 & & 4 & 2.10 \\
\hline Post-Ins & $\begin{array}{ll}5 & 12\end{array}$ & 2870 & & 10 & 1 & 2 & & 5 & $2.18 \mathrm{n} / \mathrm{s}$ \\
\hline \multicolumn{10}{|l|}{ Sc6 } \\
\hline Pre-Ins & $\begin{array}{ll}9 & 17 \\
\end{array}$ & $25 \quad 47$ & 16 & 30 & 3 & 6 & 0 & 0 & 2.25 \\
\hline Post-Ins & $\begin{array}{ll}5 & 13\end{array}$ & 1947 & 10 & 25 & 5 & 13 & & 2 & $2.45 \mathrm{n} / \mathrm{s}$ \\
\hline
\end{tabular}

$(\mathrm{n} / \mathrm{s}=$ no significant difference between the means, pre and post).

\begin{tabular}{|c|c|c|c|c|c|c|}
\hline \multicolumn{7}{|c|}{ Table 2. Frequency Distributions of Scenario Responses By Group } \\
\hline & VU(1) & $\mathbf{U}(2)$ & $\mathbf{N}(3)$ & $E(4)$ & VE(5) & Mean \\
\hline Scenario (Sc) & $\mathbf{N} \%$ & $\mathbf{N} \%$ & N \% & N\% & $\mathrm{N} \%$ & \\
\hline Sc 1: Pre-Ins $(N=48)$ & 48 & 48 & 510 & 1633 & 1940 & 3.875 \\
\hline Post-Ins(N=37) & 13 & 25 & 25 & 1130 & 2157 & 4.324 \\
\hline Sc 2: Pre-Ins & 48 & 715 & 613 & 1020 & 2144 & 3.770 \\
\hline Post-Ins & 411 & 38 & 411 & 1027 & 1643 & 3.837 \\
\hline Sc 3: Pre-Ins & 613 & 510 & 1429 & 1633 & 714 & 3.270 \\
\hline Post-Ins & 38 & 38 & 822 & 1335 & 1047 & 3.648 \\
\hline Sc 4: Pre-Ins & 1123 & 1225 & 36 & 510 & 1735 & 3.104 \\
\hline Post-Ins & 514 & 1232 & 13 & 719 & 1232 & 3.243 \\
\hline Sc 5: Pre-Ins & 48 & 715 & 36 & 2348 & 1122 & 3.625 \\
\hline Post-Ins & 13 & 25 & 13 & 1746 & 1643 & 4.216 \\
\hline Sc 6: Pre-Ins & 36 & 48 & 510 & 1940 & 1735 & 3.895 \\
\hline Post-Ins & 13 & 38 & 514 & 1643 & 1232 & 3.945 \\
\hline
\end{tabular}

(VU = very unethical, $\mathrm{N}=$ neutral, $\mathrm{VE}=$ very ethical). 


\begin{tabular}{|ll|c|r|r|r|c|}
\hline \multicolumn{6}{|c|}{ Table 3. Comparison of Pre and Post Instruction Means - Legal/Moral } \\
\hline & & \multicolumn{1}{c|}{ N } & \multicolumn{1}{c|}{ Mean } & \multicolumn{1}{|c|}{ Std. Dev'n } & \multicolumn{1}{c|}{ Sig } & Rank \\
\hline \multirow{2}{*}{ Scenario1 } & Pre & 48 & 3.8750 & 1.26533 & $* .080$ & \\
& Post & 37 & 4.3243 & 1.00150 & & 2 \\
\hline Scenario3 & Pre & 48 & 3.2708 & 1.21585 & .158 & \\
& Post & 37 & 3.6486 & 1.20684 & & 3 \\
\hline Scenario5 & Pre & 48 & 3.6250 & 1.23124 & $* * .018$ & \\
& Post & 37 & 4.2162 & .94678 & & 1 \\
& & & & & & \\
\hline
\end{tabular}

$\mathbf{l}^{*}=$ sig @.10,**=sig @.05, Rank = scenario with the biggest difference pre to post mean, of the 6 scenarios)

\begin{tabular}{|ll|c|r|r|r|c|}
\hline \multicolumn{6}{|c|}{ Table 4. Comparison of Pre and Post Instruction Means -Moral } \\
\hline & & \multicolumn{1}{c|}{ N } & \multicolumn{1}{c|}{ Mean } & Std. Dev'n & \multicolumn{1}{c|}{ Sig } & Rank \\
\hline \multirow{2}{*}{ Scenario2 } & Pre & 48 & 3.7708 & 1.37206 & .823 & \\
& Post & 37 & 3.8378 & 1.36450 & & 5 \\
\hline Scenario 4 & Pre & 48 & 3.1042 & 1.65336 & .693 & \\
& Post & 37 & 3.2432 & 1.53488 & & 4 \\
\hline Scenario 6 6 & Pre & 48 & 3.8958 & 1.17128 & .837 & \\
& Post & 37 & 3.9459 & 1.02594 & & 6 \\
\hline
\end{tabular}

(Rank = scenario with the biggest difference pre to post mean of the 6 scenarios) 


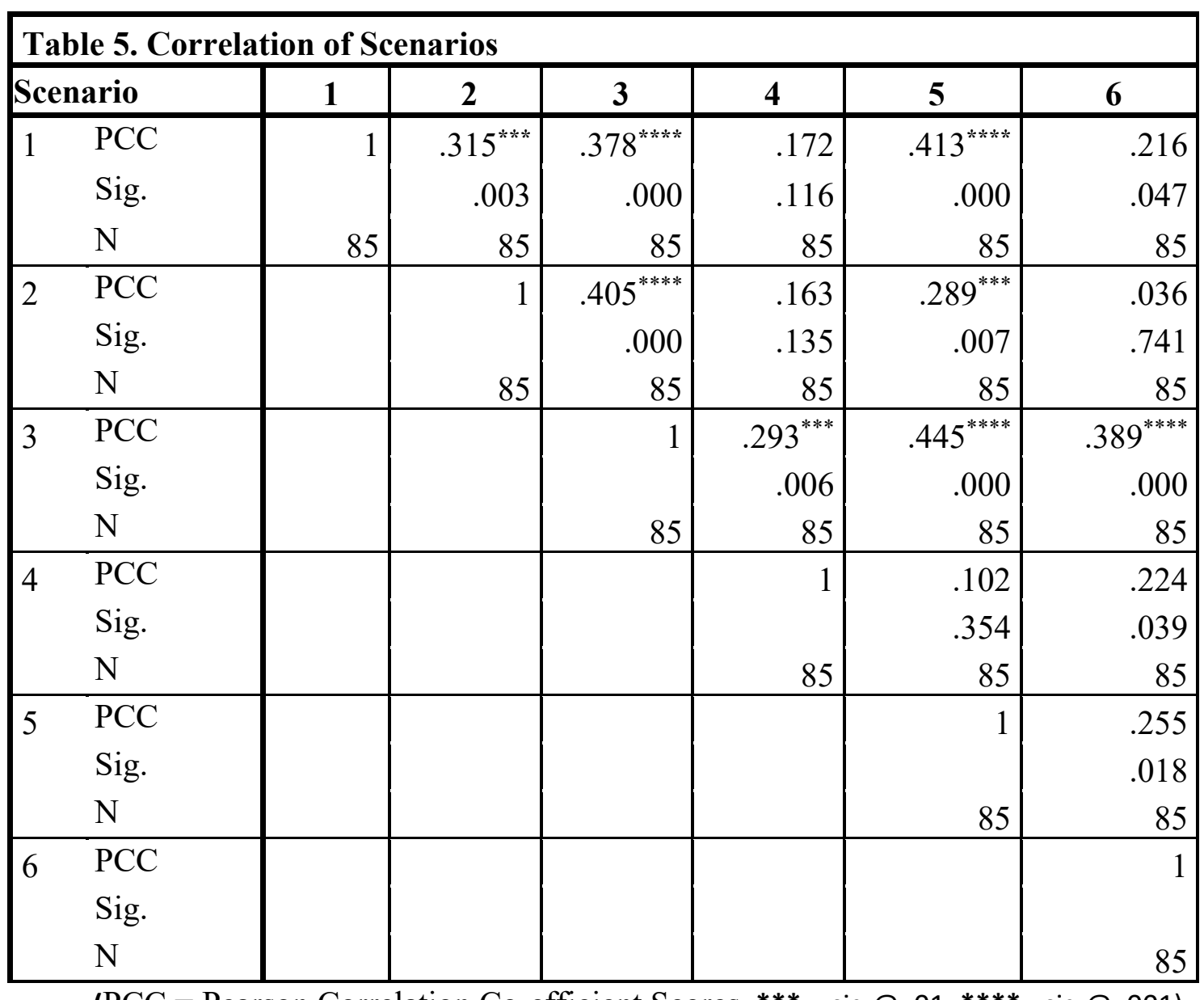

